DOI: $10.25100 /$ pfilosofica.v0i53.11188

\title{
NIETZSCHE Y LA FILOSOFÍA EXPERIMENTAL. ESTUDIOS Y PERSPECTIVAS ${ }^{1}$
}

\author{
Osman Choque \\ Albert Ludwigs-Universität Freiburg, Alemania
}

\begin{abstract}
Resumen
La expresión filosofía experimental ha cobrado un vivo interés en las recientes investigaciones sobre Nietzsche, como lo deja ver el número creciente de intérpretes. Esta reflexión ocupó un lugar pequeño en las discusiones a finales del siglo XX; situación que cambió rotundamente a comienzos de nuestro siglo. Para comprender las cuestiones que giran en torno a dicha filosofía es necesario considerar sus límites y alcances y, ante todo, el espacio que ocupa en la obra del pensador alemán. Por medio de un acercamiento filológico, el desarrollo de los últimos trabajos y los diferentes usos del concepto podremos resaltar los matices de este proyecto prometedor. Este trabajo pretende acercar al lector, por la novedad en lengua hispana, a esta discusión que va atrayendo la mirada de los interesados por el filósofo de Röcken.
\end{abstract}

Palabras clave: genealogía; filosofía experimental; el loco; filosofía alemana.

\footnotetext{
${ }^{1}$ Ich möchte mich beim Deutschen Akademischen Austauschdienst (DAAD, Promotionsstipendium) bedanken.

Cómo citar este artículo: Choque, O. D. (2021). Nietzsche y la filosofia experimental. Estudios y perspectivas. Praxis Filosófica, (53), 109-132. https://doi.org/10.25100/pfilosofica.v0i53.11188
}

Recibido: 9 de septiembre de 2020. Aprobado: 28 de octubre de 2020. 


\title{
Nietzsche and Experimental philosophy. Studies and perspectives
}

Osman D. Choque

\begin{abstract}
The expression experimental philosophy has taken on a lively interest in recent research on Nietzsche, as the growing shows number of interpreters. This reflection occupied a small place in the discussions at the end of the 20th century; a situation that changed dramatically at the beginning of our century. To understanding the questions that revolve around this philosophy, it is necessary to consider its limits and scope and, above all, the space it occupies in the work of the German thinker. Through a philological approach, the development of the latest works and different uses of the concept, we will be able to highlight the of this project promising. This work aims to bring the reader closer, due to the novelty in the Spanish language, to this discussion that is attracting the gaze of those interested in philosopher of Röcken.
\end{abstract}

Keywords: Genealogy; Experimental philosophy; Madman; German philosophy.

\footnotetext{
${ }^{2}$ Becario doctoral (Doktorand) del DAAD (Deutscher Akademischer Austauschdienst) en la Albert-Ludwigs-Universität Freiburg, Alemania. Magíster en Filosofía Contemporánea por la Universidad de San Buenaventura, Bogotá, Colombia y Especialista en Filosofía Contemporánea por la misma universidad. Estudió teología y filosofía en la Universidad Católica Boliviana. Sus intereses de investigación se centran en la filosofía clásica alemana, el pensamiento de Michel Foucault y Friedrich Nietzsche.
}

E-mail: junker.odca@gmail.com ORCID: 0000-0003-4374-8708 


\title{
NIETZSCHE Y LA FILOSOFÍA EXPERIMENTAL. ESTUDIOS Y PERSPECTIVAS
}

\author{
Osman D. Choque \\ Albert-Ludwigs-Universität Freiburg, Alemania \\ Dedicatoria: \\ „Nacht ist es: nun erwachen alle Lieder der Liebenden. \\ Und auch meine Seele ist das Lied eines Liebenden" \\ "Es de noche: ahora se despiertan todas \\ las canciones de los amantes. \\ Y también mi alma es la canción de los amantes" \\ (Nietzsche, 1996b, p. 115 [eKGWB/EH-ZA-7])
}

\section{Introducción}

La presencia de Nietzsche en los ambientes académicos y su recepción en la historia del pensamiento no comenzó en el mundo filosófico. El interés por Nietzsche fue recibido primero por poetas, políticos y, finalmente, por escritores (Choque, 2018b; Figal, 2004). A mediados del siglo XX, Heidegger posesiona al filósofo del mostacho en la historia de la filosofía. Es, en ese sentido, cierta la afirmación de que gracias a Heidegger alcanzó Nietzsche el lugar de filósofo a la altura de Platón, Kant y Hegel (Vattimo, 2001). Sin embargo, el reconocimiento que se dio a Nietzsche no resuelve que con ello se ha comprendido "correctamente" su filosofía.

Las interpretaciones convencionales de Nietzsche fijaron puntos focales, a la manera de aristas, sobre su pensamiento, tornándose estos con el tiempo irremplazables. El lector interesado en Nietzsche, por citar un ejemplo de lo anterior, debía iniciar su estudio tomando como suelo seguro los temas de la "voluntad de poder", la "muerte de Dios" y el "eterno retorno". Este 
camino, por demás apretado, dejó de lado acaso nuevas sendas de reflexión, como es el caso de la filosofia experimental ¿Es posible situar dicha filosofía dentro de las preocupaciones investigativas de Nietzsche? ¿O se trata más bien de un interés antojadizo en medio de apuntes y notas de interesados? El término de filosofía experimental se encuentra en el Diccionario Nietzsche (2012). El Diccionario describe, por un lado, la presencia de dicha noción en medio de las consideraciones de "verdad" y "error", pues, las mismas terminan en ejercicios experimentales en el filósofo y, por otro, dicho texto explica las reflexiones de Kaulbach y Gerhardt como los pioneros de esta reflexión. Nietzsche-Lexikon (2020), por su parte, desarrolla las perspectivas, sus formas y objeciones de la filosofía experimental y relaciona a la par de otros conceptos como, por ejemplo, tentador, lúdico. Lo anterior ofrece pautas de acceso a su comprensión para formular la pregunta: ¿Qué es lo que se mueve en torno a este interés léxico?

Para responder la pregunta anterior, desglosaremos tres momentos. En primer lugar, el desarrollo de un rastreo filológico de dicho concepto en las obras de Nietzsche; en un segundo lugar, posaremos la mirada en los trabajos de las recientes investigaciones que van en esta línea; finalmente, elaboraremos una reflexión a partir de textos clave para delimitar los alcances de la filosofia experimental.

\section{Análisis del concepto}

„Wir haben den guten Muth zum Irren, Versuchen, Vorläufig-nehmen wieder erobert - es ist Alles nicht so wichtig! [...] Wir dürfen mit uns selber experimentieren!“

"Nosotros hemos reconquistado el valor de equivocarse, de ensayar, de adoptar conclusiones provisionales - todo lo cual tiene ya menos importancia-, [...] Tenemos el derecho a experimentar en nosotros mismos" (Nietzsche, 2017, 251[eKGWB/M-501]).

Para un análisis de la filosofia experimental en las obras de Nietzsche es necesario considerar este concepto en un sentido bastante amplio. Dos enfoques servirán para ello: el primero nos lleva a situar los momentos en los que Nietzsche intenta, por llamarlo de algún modo, esconder su autoría u omitir su nombre; algo así como si el filósofo alemán tuviese el deseo de confundirse en otros rostros. El segundo camino va enfocado al uso estricto de la noción experimental en sus textos. Teniendo en cuenta lo anterior, 
desplegaremos el respectivo estudio en los escritos cronológicos en los que se hallan las referencias mencionadas.

Humano, demasiado Humano (Menschliches, Allzumenschliches) fue publicado en el año de 1878; una segunda edición vino después, en 1886, acompañada de un prólogo. Esta obra se distancia de textos anteriores ( $E l$ nacimiento de la tragedia y Consideraciones intempestivas) de Nietzsche en lo que respecta al uso expositivo. Al posar la mirada en las primeras publicaciones del filósofo de Röcken, el lector encuentra una escritura narrativa y, sobre todo, académica. En esa tónica, Humano ofrece novedad en el estilo, provocando un quiebre, cambiando al escrito corto, fragmentario conocido en el mundo literario como aforismo ${ }^{3}$ (usado, en especial, por los moralistas franceses en el siglo XVIII). Humano no persigue, además, los problemas planteados por Nietzsche en escritos pasados; un ejemplo de ello es el tema del arte, tan mencionado en relación a su mentor, Richard Wagner. En El nacimiento Nietzsche considera el arte a la luz de elogiosos comentarios bajo la figura del autor de "Las Valquirias" que lo describen como el epicentro de la cultura (Nietzsche, 2012; Schwab, 2011a; 2011b); en Humano, al contrario, sostiene que el arte refleja el "espíritu" (Geist) del momento cultural presente. Por otro lado, Nietzsche describe el alejamiento de cada libro en el contexto del concierto en Bayreuth: "Los inicios de este libro se sitúan en las semanas de los primeros festivales de Bayreuth: una profunda extrañeza frente a todo lo que allí me rodeaba es uno de sus presupuestos" (Nietzsche, 1996b, p. 90 [eKGWB/EH-MA-2]). Por todo ello, Humano es el desenmascaramiento de Wagner y el descubrimiento de un proyecto filosófico que le resulta cada vez inevitable. La presencia de Wagner es medular para comprender el punto de anclaje de Humano. El subtítulo "Un libro para espíritus libres" está conectado a la vocación del filósofo que Nietzsche mencionará en obras ulteriores.

Como veremos a continuación la expresión "espíritu libre" no se encuentra lejos de la filosofía experimental. Dice Nietzsche en el prefacio de Humano: "En realidad, en adelante al espíritu libre le conciernen exclusivamente cosas -iy cuántas cosas!- que ya no le preocupan" (Nietzsche, 1996a, p. 17 [eKGWB/MA I Vorrede-4] $)^{4}$. Aunque la cita ofrece varios

${ }^{3}$ Aunque el interés de este trabajo no es detallar ese "quiebre" de escritura entre los textos del pasado y la publicación de Humano, lo que sí corresponde ahondar es que no provienen de problemas de salud. Una cuestión que llamó constantemente la atención de los comentarios y levanta las orejas de los curiosos interesados. Las afirmaciones se han versado de la siguiente manera: la salud del filósofo, en especial en lo que respecta a los ojos, le exigía trabajar pocas horas (Figal, 2004).

${ }^{4}$ Las referencias remiten a la traducción del castellano y al original en alemán de la obra de Nietzsche. Luego de la citación como aparece en la bibliografía, se ha puesto en 
sentidos de interpretación, posemos la mirada en lo que expresa del "espíritu libre", en cuanto aquellas cosas que le preocupan y las que no, es decir, que "le conciernen exclusivas cosas". ¿Qué son estas cosas? El texto no ofrece respuesta dando de esa manera pautas a ilustraciones. ¿Iría destinada a la hermenéutica del espíritu o incluso de la propia filosofía nietzscheana? Interesante resaltar es la apertura sobre el posible destinatario o, inclusive, el sujeto del que se habla. ¿Es Nietzsche el "espíritu libre”? ¿No será que en este prefacio se encuentren las semillas que enriquecen el contenido? Nietzsche intenta, líneas después, distanciar a sus lectores de conclusiones acaso totalizantes y definitivas las cuales pueden aplicarse a la interpretación que se haga de su persona: "Pero todo ha devenido; no hay datos eternos, lo mismo que no hay verdades absolutas" (Nietzsche, 1996a, p. 36 [eKGWB/ MA I-2]).

La dedicatoria que Nietzsche hace a Voltaire en Humano expresa su simpatía por este autor y la influencia del ambiente científico ilustrado en su pensamiento. Este elemento ayudó a dejar de lado la concepción de arte de sus primeros escritos, dando en Humano otro significado. El poeta, por ejemplo, no se comprende a partir de entonaciones líricas y aires románticos sino mediante consideraciones científicas y, en especial, experimentales. Así lo deja ver Nietzsche: "[...] todos los poetas deben sin duda convertirse en imitadores experimentales, copistas atrevidos, por grande que sea su fuerza al comienzo" (Nietzsche, 1996a, p. 146 [eKGWB/MA I-2]). ¿Bajo qué circunstancia los poetas, según el texto, deben "convertirse en imitadores experimentales"? ¿Es Nietzsche acaso un poeta? El filósofo alemán, líneas más adelante, menciona la noción de máscara. Humano explica el uso de las máscaras como un camino que lo relaciona con su propia filosofía: "Nada de individuos, sino máscaras más o menos idealizadas; nada de realidad, sino una generalidad alegórica; caracteres de época, colores locales evaporados hasta lo casi invisible y convertidos en míticos" (Nietzsche, 1996a, p. 148 [eKGWB/MA I-2]).

Nietzsche menciona en Humano, demasiado humano, de forma primera, la noción de experimento, iniciando de esa manera un uso más o menos

corchetes la citación del texto en alemán tal como aparece en la http://www.nietzschesource. org/\#eKGWB. Primero va la abreviatura eKGWB, luego el nombre del texto y el número a que se hace referencia como se puede encontrar en la página antes mencionada. "La edición crítica digital de las obras y la correspondencia de Nietzsche al cuidado de Paolo D'Iorio y publicada por la Nietzsche Source (eKGWB) se basa en el texto crítico establecido por Giorgio Colli y Mazzino Montinari (KGW y KGB). La calidad de esta edición se basa en un riguroso trabajo de transcripción del texto de la edición impresa a la edición digital" (D’Iorio, 2010). Las referencias directas pueden encontrarse en la edición completa de Nietzsche a cargo de Colli y Montinari publicada en el 1980 (Nietzsche, 1980b). 
continuo de la misma. Sin embargo, no es posible hallar una definición exacta de la filosofía experimental, o incluso apreciaciones semi-directas que definan lo que quizá pueda comprenderse. El texto ofrece ejercicios "experimentales", es decir, estrategias de interpretación que se mueven en el terreno de la autoría. Muchas de ellas dan la impresión que el filósofo alemán tiene el deseo de separarse o escapar como autor del relato. ¿Es Nietzsche un "poeta"? ¿él es un "espíritu libre”? ¿Un "imitador experimental”? Estas preguntas brindan un panorama bastante prometedor para nuestro trabajo. Pasemos, pues, a analizar otro libro.

Aurora (Morgenröthe) fue publicada en julio de 1881 y lleva por subtítulo "Pensamientos sobre los prejuicios morales". El destino de este escrito es tan parecido a la de Humano: un fracaso rotundo. El lector familiarizado con Nietzsche afirmará sin menoscabo que esta obra va dirigida a la manera de crítica a la moral. Afirmación que se sustenta por el propio Nietzsche: "Con este libro empieza mi campaña contra la moral" (Nietzsche, 2017, p. 97 [eKGWB/EH-M-1]). Aurora es un análisis de los aspectos psicológicos y teóricos de la moral; en cuanto crítica Nietzsche repasa autores como Kant, Schopenhauer y Spencer, conocidos como fundamentos tradicionales. A raíz de lo anterior, Aurora debe comprenderse, por un lado, en el contexto temporal en el que fueron apareciendo publicaciones relativamente cercanas, como lo son Humano, demasiado humano y El viajero y su sombra (Der Wanderer und sein Schatten) y, por otro lado, fundamentalmente, en el quiebre de la relación con Wagner; un proceso entre la admiración y el rechazo que irá tomando una forma gradual. Aurora representa una nueva puesta en escena de su crítica a la moral, a partir de postulados anticristianos. Humano da pistas de esta crítica y la misma encuentra un punto álgido en Asi habló Zaratustra.

En las primeras páginas de Aurora, Nietzsche menciona las cualidades que deben poseer sus lectores. Una tarea, dice Nietzsche, para nada sencilla puesto que exige un proceso de profunda enseñanza (Nietzsche, 2017, pp. 27-33 [eKGWB/M-Vorrede 1-5]). El filósofo alemán deseaba que "aprendan a leerlo" y, sobre todo, no crean que lo han entendido. Como si se tratara de la voluntad del propio Nietzsche el no ser comprendido de modo directo. ¿En realidad, Nietzsche pretendía que no se acerquen a él si es a partir de interpretaciones finales? ¿No se trata más bien de una actitud imbuida en una forma de escritura que debe tomarse a la manera experimental? En esta perspectiva, dice Nietzsche:

Vivimos, pues, una existencia provisional o arrastramos una existencia de perezosos, según nuestros gustos y nuestro talento, y lo mejor que pode- 
mos hacer en este interregno es ser, en la medida de lo posible, nuestros propios reyes y no fundar pequeños campos de experimentación. Somos experimentos. ¡Tengamos el valor de serlo! (Nietzsche, 2017, p. 202 [eKGWB/M-453]).

Nietzsche expresa que "somos experimentos" y exige al lector estar a la altura de tal tarea y, a la vez, orientarla hacia cada uno. El filósofo alemán reconoce dichas exigencias y las voluntades de por medio. En otro texto más adelante, Nietzsche se acerca al concepto experimental y detalla la experiencia como legítima, cuya práctica se sitúa en grupos colectivos, e incluso en la humanidad. "Tenemos el derecho a experimentar en nosotros mismos. La humanidad entera tiene ese derecho" (Nietzsche, 2017, p. 215 [eKGWB/M-501]. El enunciado es claro y enfático. En Aurora hallamos un progreso conceptual respecto de la noción de experimento. Algo completamente distinto si comparamos textos anteriores. En Humano, por ejemplo, esta expresión se menciona marginalmente. Con Aurora la cuestión está dirigida especialmente a decisiones e invitaciones experimentales con base en el propio autor y hasta él mismo afirma que este sea un derecho. $L a$ Gaya Ciencia ahonda estos aportes como veremos a continuación.

La Gaya Ciencia (Die fröhliche Wissenschaft) es la tercera obra de escritura aforística. Publicada inicialmente en cuatro libros, cinco años después Nietzsche añadió un prólogo, el capítulo $\mathrm{V}$ y las "Canciones del príncipe Vogelfrei". Gran parte de los comentaristas de Nietzsche sostienen que este escrito condensa la madurez filosófica del pensador alemán (Colli, 1983; Tongeren, 1999; Choque, 2018a). La influencia de La Gaya en el círculo de lectores y críticos no se distancia del destino de escritos anteriores. El título que Nietzsche le dio es de por sí una contradicción conceptual. Por un lado, la expresión "gaya" representa el ámbito juvenil, descuidado; por otro lado, la ciencia, rigor, exactitud (Colli, 1983, p. 65). La Gaya reflexiona sobre la concepción científica, pero no en sentido estricto sino enfatiza las formas como el propio hombre comprende la ciencia. El objetivo de $L a$ Gaya radica en analizar la comprensión del conocimiento por el ser humano matizando los momentos donde la historia reprimió los instintos naturales (Colli, 1983, p. 66). Nietzsche elabora, añadiendo a lo anterior, un análisis psicológico de la historia en general. Al final del cuarto libro, denominado Incipit tragoedia, Nietzsche hace alusión por vez primera a Zaratustra, por esa razón, entre otras, La Gaya hace de puente entre dos obras, Aurora y Asi habló Zaratustra.

En el prefacio de La Gaya Ciencia hallamos la referencia que mencionamos en Aurora. Nietzsche intenta, aparentemente, esgrimir su 
responsabilidad en el texto y, de esa manera, evita las consecuencias que como autor recaen en él: "Pero dejemos a un lado al señor Nietzsche, ¿qué nos importa que el señor Nietzsche esté nuevamente sano?" (Nietzsche, 2007, p. 3 [eKGWB/FW-Vorrede-2]). Si dejamos de lado a Nietzsche, ¿qué nos queda de él? Este juego de astutas y complejas palabras va orientado a suspender por un momento la figura de Nietzsche en el relato. Según la cita, se trata de su expresa voluntad. Sin embargo, en otro número de La Gaya, Nietzsche recomienda poner la atención en uno mismo y priorizar - como lector - su persona. "Te atrae mi estilo y mi habla, me sigues, ¿vas detrás de mí? Ve fielmente sólo tras de ti: así me sigues —idespacio! ¡despacio!” (Nietzsche, 2007, p.8 [eKGWB/FW-7]).

Nuevamente, el filósofo alemán retoma el sentido de las expresiones, que vimos arriba, e invita a un juego experimental dirigido hacia sí mismo. "Pero nosotros, que somos otros, sedientos de razón, queremos mirar a nuestras vivencias con tanto rigor en los ojos, como si fuesen un experimento científico, $[\ldots]$ iQueremos ser nuestros propios experimentos y animales de prueba!" (Nietzsche, 2007, p. 184 [eKGWB/FW-319]). El texto precedente ofrece ideas acerca del juego de los experimentos. ¿Qué puede significar eso de "que somos otros"? Quizá proyectarse fuera de sí a un punto, cuidando los trazos que constituyen ese movimiento. ¿Proyecciones experimentales? Es clara la voluntad de Nietzsche cuando él afirma ese deseo. Más adelante, el filósofo hace un balance de su vida y la considera provechosa; enfáticamente dice: “¡No! ¡La vida no me ha defraudado! Antes bien, de año en año la encuentro más verdadera, más deseable, más misteriosa — desde aquel día en que vino a mí el gran liberador, aquel pensamiento de que la vida ha de ser un experimento de los que conocen-" (Nietzsche, 2007, p. 186 [eKGWB/FW-324]). Hasta este punto es innegable que es el propio Nietzsche quien manifiesta su convicción de experimentar y, por otro lado, que esta sea la forma para comprender no sólo su figura sino su escritura; evocar, en definitiva, un distanciamiento con él y con uno mismo. A raíz de todo lo anterior, hay unas líneas septentrionales que evidencian la posición de "experimentarse". Otra obra del filósofo del mostacho también va por esta línea.

La Genealogía de la moral (Zur Genealogie der Moral) se publicó en los meses del año de 1887. Se trata de una obra única y especial en la producción del filósofo alemán y en la historia misma de la filosofía. Es el primer escrito en donde el estilo aforístico no conforma totalmente el libro, sino que Nietzsche elabora su escritura en partes; divide el mismo en tres "tratados" claramente diferentes de cada uno. La posteridad supo dar un lugar 
especial a La Genealogía en la medida en que este ha permeado los campos de la sociología, la antropología y la psicología. Por otro lado, Nietzsche introduce el término de genealogía; un concepto hasta ese entonces nuevo en la filosofía. Con esta noción, el pensador alemán no busca realizar una historia "sencilla" del origen de la moral, al contrario, plantea perseguir el rastro de la moral desde el presente hasta los momentos o lugares donde las prácticas se han perdido, se han difuminado y en cuyas huellas sólo encontramos incertidumbres. Nietzsche describe, en ese sentido, la historia de los referentes morales no a la manera de un único árbol sino de "muchos" árboles genealógicos; la moral se forma, entonces, bajo caminos múltiples. Si es posible hablar de una "historia de la moral" esta estaría compuesta de hipótesis y de diversas procedencias. Por ello, los "tratados" que componen La genealogía elaboran a su modo una tesis bajo el prisma genealógico.

La genealogía no ofrece alusiones sobre juegos o ejercicios experimentales; pero, sí describe, una vez más, el deseo de ficción o sospecha en la voluntad de Nietzsche al momento de comprenderlo. Para ello, toma la idea del artista cuando este analiza su trabajo y enfatiza la libertad y el distanciamiento con sus proyectos. "[...] como todo artista, alcanza la última cumbre de su grandeza tan sólo cuando sabe verse a sí mismo y a su arte debajo de sí, cuando sabe reírse de sí" (Nietzsche, 1980a, p. 130 [eKGWB/GM III-9]).

La reflexión hasta aquí elaborada ofrece un rico panorama. Por un lado, la noción de experiencia, con sus variantes experimental o experimentos, recorre varias obras de Nietzsche y el uso del concepto es relativamente frecuente; por otro lado, el deseo del pensador alemán de "confundir" al lector cuando este pretende entenderlo es reiterado; finalmente, Nietzsche considera como un camino proyectarse en determinadas figuras a la manera de experimentos. Frente a lo anterior, hay una vía aparte en la que podemos posar la mirada como fuente de investigación: los Fragmentos Póstumos.

En los Fragmentos Póstumos (Nachlaß) se encuentran los apuntes, materiales preparatorios que giran en torno al tiempo en que fueron apareciendo las obras de Nietzsche. Una colección de notas durante los años de 1869-1889. Ante la opinión de Heidegger que los Nachlaß condensan la filosofía de la "voluntad de poder" de Nietzsche (Heidegger, 2013) este juicio no ofrece una interpretación objetiva en el uso de dichos fragmentos. Estos tienen un lugar importante en cuanto horizonte investigativo en la medida que permiten rastrear ideas de Nietzsche, los cambios de planes de los proyectos, incluso algunos inacabados; pero, no puede reducirse toda la filosofía del pensador alemán, como pretendió Heidegger, a la lectura exclusiva de los mismos considerando que con ello se obtendría 
una "comprensión definitiva" del filósofo del mostacho. Ahora bien ¿Hace alusión Nietzsche sobre la filosofia experimental en estos textos? De ser así ¿En qué consisten esas referencias? ¿Acaso se diferencian de las apreciaciones que hemos desglosado?

La voluntad de poner en sospecha las "correctas" interpretaciones y, de la misma manera, distanciarse de los lectores y el impulso de juegos experimentales están presentes en los Fragmentos Póstumos. Dice Nietzsche: "La más extrema desconfianza frente al intelecto entendido en cuanto herramienta de las pulsiones: el aborto de la soberbia es el escepticismo" (Nietzsche, 2008, p. 609 [eKGWB/NF-1880, 6(31)]). Llama la atención el uso de la noción de escepticismo en lugar de experimental. En otro texto, el pensador alemán cita una vez más la expresión. El escéptico, según Nietzsche, no evoca una actitud de duda hacia sí mismo o de lo conocido, sino que pone en tela de juicio el hecho de afirmar que se consiguió cuanto se proponía. ¿Un tipo de escepticismo distinto y del que se desprenda enseñanzas "positivas"? En el siguiente fragmento, Nietzsche usa el concepto experimental y adiciona, para nada mencionado hasta el momento, el de ensayo.

Ya que somos escépticos, nuestras acciones son experimentos, cálculos con algunas magnitudes desconocidas - muy interesantes, por lo tanto, porque no se trata de manifestaciones pueriles de nuestro poder que, cuando fallan, nos disgustan, sino de ensayos que, cuando resultan logrados, nos permiten obtener cierta información acerca de lo que sea. No dejamos que nos tiranicen ni las acciones ni los logros (Nietzsche, 2008, p. 677 [eKGWB/ NF-1880, 6(442)]).

Los fragmentos mencionados fueron redactados alrededor de los años de 1880, es decir, el tiempo en que fue publicado Aurora. El siguiente fragmento fue escrito en el momento de publicación de Así habló Zaratustra. Nietzsche cita su deseo de ser un hombre distinto, algo completamente otro a la hora de analizarlo. "Y cuando el juicio de valor parece determinar a un hombre, ¿no tiene lugar, en el fondo, algo completamente distinto?" (Nietzsche, 2010, p. 448 [eKGWB/NF-1883, 24(16)]). Dado que este fragmento se redactó en los periodos de escritura de Zaratustra, es posible lanzar las preguntas ¿Quién es el "distinto" que menciona Nietzsche?, ¿Acaso Zaratustra?

Finalmente, en un fragmento del año de 1888 que gira en torno a la publicación de El Anticristo, Nietzsche expresa la relación de su vida con la filosofía o más aún con su capacidad de filosofar. El filósofo alemán se pregunta sobre las características de su igual. 
En qué reconozco a mi igual - La filosofía, tal como yo la he entendido y vivido hasta ahora, es la búsqueda voluntaria incluso de las caras más malditas e infames de la existencia. De la prolongada experiencia que me ha proporcionado ese caminar por el hielo y el desierto yo he aprendido a considerar de otro modo todo lo que se ha filosofado hasta ahora: - se me han puesto al descubierto la historia oculta de la filosofía, la psicología de sus grandes nombres. «¿Cuánta verdad soporta, cuanta verdad osa un espíritu?» - esto se convirtió para mí en el auténtico criterio de valor. El error es una cobardía... toda conquista del conocimiento es consecuencia del coraje, de la dureza consigo mismo, de la limpieza consigo mismo... Semejante filosofía experimental, como yo la vivo, anticipa a modo de ensayo incluso las posibilidades del nihilismo radical: sin que con ello se haya dicho que permanezca en un no, en una negación, en una voluntad de no (Nietzsche, 2016, p. 677 [eKGWB/NF-1888, 16(32)]).

En el fragmento precedente, rico en contenido, Nietzsche cita la noción de filosofia experimental y, además, ofrece una definición, quizá la primera. La filosofia experimental es, para Nietzsche, un juego ensayístico. El punto álgido de la cuestión se ubica en el anterior fragmento porque en él Nietzsche lleva a cabo un intento de "conceptualización". La experiencia, para Nietzsche, es el "uso de ensayos" en dos sentidos. Por un lado, como respuesta ante un respectivo problema y, por otro, como una herramienta hermenéutica de la propia existencia. Estos sentidos aparecen en Ecce Homo "nada que sea distinto ni en el pasado ni en el futuro ni en la eternidad" (Nietzsche, 1996b, p. 18 [eKGWB/EH-Klug-10]) en el año en que fue escrito el fragmento 1888. La riqueza de matices que enfatizan la expresión filosofia experimental va cobrando forma de manera paulatina o incluso se adhiere a un pensar discontinuo (Choque, 2019b).

A partir de lo descrito cobra evidencia que el concepto de experimento, con sus variantes, está presente en la obra de Nietzsche; pero, por la singularidad del tema y el formato de publicación, un desglose acabado de "tipologías" de significado exige de otros momentos. Las recientes investigaciones sobre Nietzsche describen nuevas vías de acceso en cuanto la filosofia experimental se explica a la luz de la escritura del filósofo alemán, es decir, puntualizan la relevancia en textos o figuras clave de su obra. Estas investigaciones desglosan, ante todo, formas metodológicas de la filosofía experimental a la manera de un tipo de ejercicio "programático", por llamarlo de algún modo. Una cuestión que explicaremos a continuación. 


\section{III. ¿Qué es la filosofía experimental?}

El interés por esta expresión, como una cuestión relacionada con las relevantes preocupaciones investigativas de Nietzsche, apareció en el contexto alemán a finales del siglo $X^{5}$. Friedrich Kaulbach (1980) divulgó su obra Nietzsches Idee einer Experimentalphilosophie. Por su parte, Volker Gerhardt (1986) sacó a la luz un texto titulado " ExperimentalPhilosophie'. Versuch einer Rekonstruktion". A inicios del siglo XXI, Philipp Schwab (2015) publica su escrito "Critique of 'the System' and Experimental Philosophy - Nietzsche and Kierkegaard" y, finalmente, Andreas Urs Sommer (2019) presenta su trabajo Nietzsche und die Folgen. Estos planteamientos sacan a la luz interesantes matices que, sin dudarlo, demuestran diversos acentos, puntos focales y conclusiones. Las últimas publicaciones - Schwab y Sommer -, sin embargo, dan a un paso adelante, porque lo anterior "no ha conducido hasta la fecha al establecimiento de un paradigma investigador mínimamente aceptable" (Heit, 2012, p. 206), y ofrecen aspectos frescos y alcances novedosos de la filosofía experimental. Por un lado, Schwab sitúa su reflexión entre dos momentos claves, a saber, una filosofia experimental como "crítica" y, además, "afirmativa". Sommer enfatiza que esta filosofia fue utilizada por Nietzsche a la manera de artificios literarios y está presente en sus obras. A continuación, desglosaremos estos postulados.

En el texto "Critique of 'the System' and Experimental Philosophy - Nietzsche and Kierkegaard"6, Schwab describe la "posible" relación entre Nietzsche y Kierkegaard. A primera vista, esta conexión traería pocas vicisitudes en cuanto a sus focos de interés, puesto que uno es tan distinto al otro; el último valora el cristianismo, mientras que el primero lo critica. Sin embargo, para Schwab, hay varios elementos que reducen esta distancia. Tanto Nietzsche como Kierkegaard diagnosticaron la crisis de la modernidad, por un lado, y, por otro, esta crisis se debe a la noción en sí misma de sistema, como característica irreductible (Schwab, 2014).

${ }^{5}$ Choque afirma "Hasta hace poco se empieza a hablar de la 'filosofía experimental' en el pensamiento de Nietzsche. Esta novedosa forma de acercarnos al filósofo de Röcken se debe específicamente a las reflexiones de Andreas Urs Sommer, un eminente intérprete de Nietzsche" (Choque, 2018a, p. 1). La cita anterior debe matizarse. Por un lado, en habla hispana sólo se han traducido algunos artículos de Sommer y, por tal razón, la literatura en español sobre la "filosofía experimental" es prácticamente nula. Por otro lado, recurriendo al argumento de la cita "hasta hace poco se empieza a hablar" es totalmente correcta, aunque antes de Sommer existan otros autores. El contexto hispano le da el sentido que corresponde a la cita (Choque, 2020a; Choque 2020b).

${ }^{6}$ Traducción del autor 
Frente a ello, ambos pensadores, dice Schwab, usaron con frecuencia un "método experimental" como postura crítica.

[E]n ambos pensadores, el método experimental respectivo apunta a un carácter irreductible de la perspectiva de la cognición y la existencia, y se corresponde con el supuesto de que la actualidad es esencialmente devenir y no ofrece un resultado final y definido. Así, tanto en Kierkegaard como en Nietzsche, la forma experimental de pensamiento no debe entenderse (mal) como un mero "uso" de "recursos literarios o retóricos". Más bien, afecta la "sustancia" misma de sus respectivas filosofías (Schwab, 2015, p. 225).

¿En qué sentido el método experimental "afecta la 'sustancia" de sus filosofías? Para Schwab existe un tipo de escritura experimental a la manera de hilos constitutivos en la obra de cada filósofo y, por su parte, la misma fecunda la forma de pensar de Nietzsche. La conclusión que se desprende de lo anterior, por el momento, plantearía una "extremada prudencia" a la hora de acercarnos al filósofo alemán. Schwab traza las características de la filosofía experimental en cuanto método, es decir, su estructura interna y

122 lógica de proceder. Dicha filosofía se desplazaría por medio de dos canales: "una filosofía experimental crítica y una filosofía experimental 'afirmativa' [en Nietzsche])" (Schwab, 2015, p. 236). Expliquemos ambos caminos.

La filosofía experimental crítica está condensada en la crítica del "sistema", es decir, el rechazo de Nietzsche a los sistemas de pensamiento de la modernidad. La filosofía experimental es el método, según Schwab, que utilizó el filósofo alemán para sustentar y llevar a cabo su objetivo: "Nietzsche critica las formas tradicionales de pensamiento reconstruyendo el proceso y las condiciones de su formación." (Schwab, 2015, p. 236). El lugar de Humano tiene relevancia en la producción escrita del filósofo de Röcken, en especial, como vimos arriba, por el uso del aforismo. En ese sentido, Schwab enfatiza este punto como el inicio de su filosofar. En el prefacio de Humano, Nietzsche menciona la noción de sospecha (es conocida la sentencia de Ricoeur al respecto) como forma de su trabajo "Schule des Verdachts" (eKGWB/MA-I-Vorrede-1), una escuela de la sospecha. Schwab toma esa cita a la hora de considerar la crítica al sistema ya que Nietzsche no pretendió elaborar un sistema de pensamiento sino algo tentador, una filosofia tentadora: "su crítica toma la forma de un intento o una empresa, es una forma de filosofía 'tentadora' (versucherisch)" (Schwab, 2015, p. 237). En ese contexto, Schwab afirma que el método es una cuestión intrínseca de la filosofía experimental en cuanto Nietzsche usó experimentos (tentadores), evitando así esquemas o trabajos sistemáticos en sus escritos. 
La filosofía experimental "afirmativa" ilumina, por su parte, la noción de nihilismo. Como sucede con los conceptos importantes de Nietzsche estos tienen muchas definiciones y el nihilismo obedece a lo anterior. La frase "la trágica superación del nihilismo", que se encuentra en los Fragmentos Póstumos (Nietzsche, 2016), nos permite imaginar que en el nihilismo existió un antes y, de ese modo, un después. Un antes que fue superado quedando de esa manera un pasado del primero y un futuro del segundo como fruto del nihilismo. Para Schwab, esa conclusión acelerada, como el lector comprenderá correctamente, no debe ser el final de la interpretación. La superación del nihilismo es un juego experimental. En ese mismo sentido se halla otra afirmación del nihilismo, esta vez como "devaluación de los valores". Si los valores tradicionales inician su crepúsculo posiblemente vendrán otros para llenar esos vacíos. A partir de lo propuesto, crearíamos, según Schwab, otros valores en los que han dejado de ser. Dando de esa forma posibilidades, o momentos provisionales, de creación continua de valores, en el fondo experimentales. "En este sentido, la posición trágica de valores es irreconciliablemente procedimental y provisional, y en este sentido, 'experimental"' (Schwab, 2015, p. 241). Si Nietzsche afirmó que "no hay mundo verdadero" (Nietzsche, 1973; Schwab, 2016) la aparición espontánea de valores es permitida.

Schwab, a partir de los caminos descritos, enfatiza el uso del "método experimental" y el sitio de la filosofía experimental. Esta filosofía más que configurarse a la manera de una presencia dispersa en la obra de Nietzsche forma parte constitutiva de su pensar. En definitiva, la filosofía experimental actúa, según Schwab, como herramienta interpretativa. Al parecer, la filosofía experimental "crítica" y "afirmativa" están unidas y permeadas: la crítica de los sistemas de pensamiento de la modernidad conduce a considerar el nihilismo (como consecuencia de la crisis de la modernidad); pero dicha cuestión está en movimiento, entre un antes y un ahora aún no definido. Entonces, el nihilismo por sí mismo es experimental. En tanto Nietzsche no consideró elaborar un sistema de pensamiento, sus convicciones o afirmaciones filosóficas no podrían darse como "últimas" y "finales". Toda afirmación en materia nietzscheana tendría que ser ella experimental.

Con la publicación de Nietzsche und die Folgen el pensador suizo explicó las líneas maestras de una nueva lectura de Nietzsche. Lejos de la interpretación conocida convencionalmente, los temas que Sommer describe son variados; pero, en lo que respecta a la filosofia experimental, el pensamiento de Nietzsche estaría marcada, según Sommer, por un juego experimental, a la manera de "ejercicios literarios". El lector tiene la tarea de "enfrentarse" con el texto, pues no cuenta con la seguridad ni la certeza 
de haber comprendido el mensaje: "Nietzsche es un filósofo que utilizó la enseñanza como un experimento intelectual y existencial. Su filosofía no es una enseñanza, sino un acto, una práctica de pensar para transformar el mundo" (Sommer, 2019, p. 2) ${ }^{7}$. La filosofía de Nietzsche, para Sommer, invita al lector a pensar, a considerar el trabajo mental como estrictamente necesario para acercarse a su filosofía. Por tal razón, una labor imprescindible es que los lectores se aparten de las tradicionales interpretaciones del pensador alemán donde su pensamiento estaba enfocado en los tres clásicos tópicos: "El eterno retorno", "la voluntad de poder" y el "superhombre".

Sommer pone al descubierto los límites de lecturas convencionales de las obras de Nietzsche. Dichas lecturas "tradicionales", por llamarlas de algún modo, más que ahondar en las riquezas de su pensamiento encasillaron sus ideas o, en algunos casos, fueron a contra vía de interesantes puntos focales de la filosofia nietzscheana. La filosofía experimental se encuentra como un ícono inadvertido. Sommer es consciente, pues, que este interés apenas llamó la atención del auditorio: "Para esta filosofía [experimental], sin embargo, Nietzsche apenas encontró audiencia entre contemporáneos más indiferentes" (Sommer, 2019, p. 35).

Sommer, además, considera en su reflexión varios pasajes representativos de los escritos de Nietzsche. Estos temas y personajes que aparecen en el parágrafo125 de La Gaya Ciencia, Zaratustra, el loco, etc., acentúan la presencia de la filosofía experimental. Según Sommer, la tarea de estas figuras no consiste en llevar el mensaje de Nietzsche, sino que forman parte de un ejercicio experimental. Dichas figuras llevan al lector a fomentar la creación de imágenes o escenas creativas: "Los personajes de ficción literaria son característicos del filosofar experimental de Nietzsche. La actuación y el habla de los personajes de ficción liberan al filósofo experimental de tener que comprometerse con cualquier punto de vista o doctrina en particular" (Sommer, 2019, p. 48). Un ejemplo singular de lo anterior es la figura de Dios. La profecía de la "muerte de Dios" tal como se lee en una obra de Nietzsche no tendría el fin de explicar o menos aún ejecutar el querer de Nietzsche en cuanto tenga el deseo de confirmar su hipótesis. Se trata más bien del anuncio de un "hecho" imaginario: "Quizás el diagnóstico de la muerte de Dios no debe entenderse como la doctrina dogmática de Nietzsche, sino como una hipótesis filosófica experimental" (Sommer, 2019, p. 49). Quien esté familiarizado con Nietzsche se preguntará, entonces, ¿cuál es el sentido de todo esto?, ¿a dónde nos lleva las reflexiones del filósofo alemán? Sommer considera que las "doctrinas" de Nietzsche invitan al

${ }^{7}$ Traducción del autor 
interlocutor a imaginar, a partir de ellas, un posible suceso; que el lector piense, experimente, reflexione lo que al parecer acaecerá en el futuro. Dice Sommer: "Estas supuestas 'doctrinas principales' son experimentos de vida y pensamiento o, en otras palabras, mitos experimentales" (Sommer, 2019, p. 60). Una invitación a examinar la gama de facetas personales e ideas que se desprenden del pensamiento de Nietzsche. La pluralidad, en definitiva, de su mismo filosofar. "Quienes se toman muy en serio a Nietzsche se ven obligados a silenciar la polifonía de Nietzsche" (Sommer, 2019, p. 109).

El tercer momento de este trabajo irá dedicado a explicar la filosofía como un experimento. Se realizará un acercamiento a la obra del filósofo de Röcken para intentar responder la cuestión ¿En qué consiste realmente la filosofia experimental de Nietzsche? Para ellos nos detendremos en momentos puntuales de su pensamiento.

\section{IV.La filosofía como experimento}

La filosofía experimental se encuentra en varios pasajes de la obra de Nietzsche ${ }^{8}$, pero hay dos textos de los que es posible extraer un contenido rico y fecundo para nuestro interés. Se tratan del parágrafo 125 de La Gaya Ciencia y el texto denominado El caminante y su sombra.

La Gaya Ciencia se publicó por primera vez el año de 1882. Nietzsche añadirá un quinto libro "Wir Furchtlosen" y un apéndice "Lieder des Prinzen Vogelfrei". La recepción de esta obra, para disgusto del propio Nietzsche, continuó la penosa herencia de escritos anteriores, la indiferencia del mundo intelectual y la poca atención de la crítica. "[...] como autor de Humano demasiado humano, Aurora y La Gaya Ciencia [Nietzsche] había quedado ignorado y desconocido" (Hollingdale, 2016, p. 172). Sin embargo, el éxito de esta publicación vino décadas después como lo deja ver la historia de las interpretaciones (Fink, 2017; Heit, 2014; Niemeyer, 2012, Sommer, 2019; Schwab, 2015). La raíz de la popularidad que La Gaya alcanzó se debe al estilo, una escritura madura y cuidadosa, de Nietzsche y al contenido mismo, en especial, porque contiene el parágrafo 125 titulado "El loco" (Der tolle Mensch), en cuyas líneas se encuentra la frase "Dios ha muerto".

En primer lugar, el número 125 de La Gaya Ciencia no se trata de un aforismo, estilo tan frecuente de Nietzsche, sino que por la extensión para la ciencia literaria es un parágrafo. En segundo lugar, este parágrafo ha llamado la atención de un sinnúmero de comentaristas e intérpretes a tal punto que ese interés no tiene competencia con ninguno de sus textos. La historia de las interpretaciones muestra que tanto el campo religioso como el ateo

\footnotetext{
${ }^{8}$ Existe, a decir verdad, una rica veta de investigación en otras obras como Aurora y, sobre todo, Ecce Homo.
} 
se han sentido interpelados por el contenido de dicho escrito. Lo anterior resulta comprensible, y más aún a partir del prisma religioso. ¿Qué quiso decir el loco al anunciar la "muerte de Dios"? ¿Qué significa que "Dios ha muerto"? Para explicar este texto nos serviremos de dos momentos a la manera de hilos conductores interpretativos: la presencia del loco y su mensaje y, finalmente, la respuesta de la gente del mercado.

“No habéis oído hablar de ese hombre loco [...]?” (Nietzsche, 2007, p. 114 [eKGWB/FW-125]), de esa manera inicia el parágrafo 125. Pero, ¿a quiénes se dirige el texto? ¿Quiénes son los que "no habéis oído"? La Gaya no ofrece información al respecto. Esta aproximación es una vía interpretativa: no poseemos referencia sobre los destinatarios o los posibles oyentes. Podemos sospechar, con bastante astucia, que el escrito va dirigido al mundo religioso. $\mathrm{O}$, con razón, deducir que los receptores pertenecen al gremio filosófico. ¿El parágrafo 125 está orientado a uno de los casos anteriores? Por el momento, este acercamiento nos lleva a la conclusión de que esa pregunta tiene un enfoque experimental (Sommer, 2006; 2019; Choque, 2020a). Volveremos a esto más adelante.

El relato continúa con el primer discurso en la voz del loco: "Busco a Dios, Busco a Dios" (Nietzsche, 2007, p. 114 [eKGWB/FW-125]). Esta búsqueda refleja que el loco es creyente y es el portavoz (Sprecher) del mensaje. La gente del mercado escucha el mensaje, pero se burlan del mismo: “¿Es que se te ha perdido?” (Nietzsche, 2007, p. 115 [eKGWB/ FW-125]). Lo que sucede es que la gente escuchó por primera vez que "Dios ha muerto" y sus ironías no vienen de esto, sino que ellos no tienen conocimiento del futuro que le "espera" a la humanidad tras dicho evento. "Pero los hombres, a los que el hombre loco encuentra en el mercado, no son creyentes; por primera vez oyen que Dios ha muerto" (Sommer, 2006,

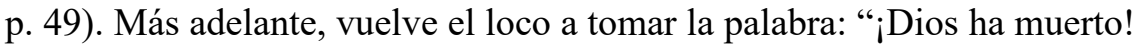
¡Dios permanece muerto! ¡Y nosotros lo hemos matado!” (Nietzsche, 2007, p. 115 [eKGWB/FW-125]). La frase "nosotros lo hemos matado" expresa que los lectores son herederos del "acontecimiento" y sólo en ese sentido este parágrafo nos invitará a meditar ese lugar incierto. Por otro lado, este relato ejemplifica la filosofía experimental ya que el parágrafo 125 desprende una pregunta quizá difícil de dar respuesta: ¿Quién es el loco? ¿Nietzsche, un filósofo aún desconocido o incluso la sociedad representada en esa apariencia? En la medida en que esa cuestión quede abierta, invita a leer esas líneas como un "artificio literario". "Dicho artificio no tiene la tarea de transmitir ideas filosóficas, que serían en ese caso las de Nietzsche, sino la de llevar al lector a una posible ilustración de las mismas" (Choque, 2019a, p. 144). Por lo anterior, el loco esgrime la figura del autor del texto, 
Nietzsche, para crear un espacio simpático de creaciones e interpretaciones $y$, sobre todo, de ejercicios mentales. Nietzsche busca provocar a sus lectores $\mathrm{y}$ retarlos inteligentemente.

Otro momento del relato es el mensaje. El loco llega ante la gente del mercado. A partir de la enseñanza popular podemos deducir el contexto. La palabrería y los chirridos son frecuentes y el bullicio es casi absoluto en el mercado evitando la comunicación directa y clara. La conversación entre el loco y la gente del mercado, por lo tanto, tiene dificultades. Según el texto, el loco desea comunicar su mensaje al margen del difícil ambiente y expresa sus palabras ante la gente y, por otro, al final del mismo, menciona que este ha llegado tarde: "Este acontecimiento inaudito aún está en camino" (Nietzsche, 2017, p. 115 [eKGWB/FW-125]). ¿Qué es lo que "está en camino"? ¿Acaso la interpretación o se trata más bien de un ejercicio experimental $a$ posteriori?

Como último momento del relato nos encontramos con la respuesta de la gente del mercado. El texto menciona que un grupo de personas estaban reunidas y responden con una carcajada al mensaje del loco: " ¿Es que se ha perdido?», dijo uno. "¿Se ha extraviado como un niño?», dijo otro" (Nietzsche, 2007, p. 115 [eKGWB/FW-125]). El loco contrarresta esas carcajadas y, lanza fuertemente su mensaje: “¡Nosotros lo hemos matado —vosotros y yo! ¡Todos nosotros somos sus asesinos! ¿Pero cómo hemos hecho esto?” (Nietzsche, 2007, p. 115 [eKGWB/FW-125]). Ahora bien, ¿qué expresa lo anterior? La gente del mercado toma en sentido literal las palabras del loco y por ello ironiza su contenido y lo lleva hasta el absurdo. El loco pretende crear un ambiente ficticio y diagnosticar el "futuro" que sigue a la "muerte de Dios”. "¿Con qué agua podremos limpiarnos? ¿Qué fiestas expiatorias, qué juegos sagrados tendremos que inventar?" (Nietzsche, 2007, p. 115 [eKGWB/FW-125]). Él deja de "buscar a Dios" y diagnostica una situación experimental. El parágrafo más adelante remite a una larga lista de preguntas que tienen la tarea de provocar posibles situaciones: "¿quién nos lavará esta sangre? ¿Con qué agua podremos limpiarnos?” (Nietzsche, 2007, p. 115 [eKGWB/FW-125]). La escena termina con las palabras del loco advirtiendo que este llegó prematuramente: "«Llego muy temprano»" (Nietzsche, 2007, p. 115 [eKGWB/FW-125]). Entonces, el loco no pertenece a un tiempo real y concreto; es un individuo atemporal, o en todo caso fuera de la historia. De ahí que las preguntas de la cita anterior reflejan que su presencia, y su mensaje, en medio de ellos es prematura: "Lo que les falta es la conciencia del alcance de ese hecho" (Sommer, 2006, p. 49).

Las figuras literarias son frecuentes en la obra de Nietzsche. Como vimos arriba, la figura del loco es medular para la filosofia experimental. Existe, además, otro texto muy sugerente en El caminante y su sombra (Der 
Wanderer und sein Schatten). Este libro fue escrito en el año de 1878 como proyecto de Humano, demasiado humano. En El caminante se encuentra el parágrafo titulado "Los presos".

Una mañana salieron los presos al patio a trabajar; el carcelero se hallaba ausente. Unos, como tenían por costumbre, se dedicaron inmediatamente a trabajar, pero otros se quedaron sin hacer nada y miraban a su alrededor con aire provocador. Entonces salió uno de las filas y dijo a voces: «Haced lo que queráis: trabajad o no trabajad; da igual. El carcelero ha descubierto vuestros secretos manejos y va a castigaros muy duramente. Ya sabéis que es implacable y rencoroso. Pero escuchad lo que os voy a decir: hasta ahora no me conocíais; yo no soy lo que pensáis. Soy el hijo del carcelero y puedo lograr de él cualquier cosa (Nietzsche, 1999, p. 80 [eKGWB/WS-84]).

¿Quiénes son los presos y de la misma forma el carcelero? ¿Quién es el preso que rompe las filas? A primera vista, el texto no explicita datos relevantes de la precedencia del preso. Lo anterior es una interesante pista interpretativa. La filosofía experimental toma la iniciativa y lanza la invitación a no considerar los personajes como reales, históricos y, sobre todo, de gran influencia ulterior. Se trata, pues, de ironías literarias, de ejercicios experimentales. Más adelante el preso afirma: "Haced lo que queráis" ¿Es acaso una frase que va en la tónica del loco del parágrafo 125 ? ¿Quién podría afirmar que "todo está permitido"? La sentencia "Haced lo que queráis" no pretende fundamentalmente erigir un tipo de susceptibilidad en la vida moral de los sujetos sino invitar a los mismos a imaginar el hechos o situaciones. La tarea del preso, que continúa la línea del loco, es provocar la mente del lector y que este pronostique las consecuencias.

Una clásica interpretación de Nietzsche formuló dos sentidos hermenéuticos de su pensamiento. Por un lado, la relevancia de temas estrictamente puntuales en la filosofía del hombre del mostacho y que estos deben considerarse como expresión ad litteram de su propio pensar. Por otro lado, las predicciones de Nietzsche se configuran como hechos reales cuya profecía acaecerá de forma definitiva en el futuro. Pues bien, según intentamos explicar, la filosofía experimental sitúa al lector en otro horizonte de comprensión.

\section{V.Conclusión}

La figura del filósofo se pierde en su amplio y exuberante mostacho. Las miradas consideraron este mostacho atusado en tono extravagante. En el mundo filosófico, su bigote lo identifica, lo destaca y distingue del 
resto y le otorga una silueta ciertamente reverente y prometeica. Vemos su mostacho en cuadros y pinturas. En ocasiones, el filósofo se encuentra solo, aunque tejió una red de muchos amigos. Algunas fotografías expresan al hombre, bajo una mirada perdida, tendido en el sofá con el bigote inmutable; el mostacho expresa el rostro y el trabajo del filósofo. Su mostacho, dicen los intérpretes, "obliga a tomar decisiones últimas" (Fink, 2017, p. 7). Interpretaciones azarosas dejaron de lado la vida del pensador y esperaron que hable el bigote por encima de todo. Su carismático mostacho dio a hablar de manera prolongada en la historia del pensamiento. Sólo quedó al final el bigote y sus frases.

En una obra emblemática, Ecce Homo, en el apartado "Por qué soy un destino" escribe el filósofo de Röcken “¿Se me entiende?” (Nietzsche, 1996b, p. 137). Nietzsche se pregunta si realmente los lectores lo comprenden. Es una interrogante sugerente porque permite poner en "sospecha" lo que, por un lado, sabemos de él y, por otro, lo que él mismo pretendió dar a conocer. Lo anterior no puede llevarnos a un terreno movedizo y sin salida para deambular sin horizonte. Las recientes investigaciones (Tongeren, 1999; Müller, 2020; Sommer, 2006; Schwab, 2015) dan luces e indudablemente ofrecen un camino ante el desconcierto. Como mencionamos líneas arriba, un primer paso para acercarnos al pensamiento de Nietzsche consiste en dejar entre comillas la hermenéutica que se ha hecho sobre él, es decir, dejar de lado los "grandes tópicos" de su filosofía (Choque, 2020b). "La voluntad de poder", "el eterno retorno" y "el superhombre" si bien son temas que abundan en la bibliografía, estas no permiten ver lo novedoso del filósofo.

Es posible afirmar que varias insinuaciones de investigadores sobre Nietzsche de habla hispana no estaban lejos de la filosofía experimental. Un texto de Eugenio Trías es un caso notable al respecto. En un prólogo titulado "El 'experimentum crucis' de la filosofía de Nietzsche" dice el filósofo español: "¿Y si el 'eterno retorno de lo mismo' fuese únicamente una prueba! [...] La doctrina del "eterno retomo de lo mismo" aparece [...] como la última gran carga que tiene que soportar el pensador, el filósofo, es decir, el hombre que experimenta" (Trías, 1987, pp. 7-8). Trías pone en suspenso el sentido de los famosos temas del filósofo alemán, como es el caso del "eterno retorno", para mencionar que estos deben llevar al hombre a experimentar. En el mundo alemán encontramos, nuevamente, referencias sobre la prudencia y distancia que se debe tomar para comprender a Nietzsche: "Nietzsche trabaja continuamente la distancia que es necesaria para el análisis y la descripción; y sabe que su distancia no solo se logra, sino que también es posible, es decir, dependiendo de las condiciones que no se aplican a ella" (Figal, 2004, p. 17). 
La filosofía experimental de Nietzsche, como lo explica Schwab, va unida a la expresión de nihilismo. En ese sentido, esta noción puede explicar el uso de los experimentos. Es más, el nihilismo forma parte del artificio experimental a la manera como si fuera el propio autor quien reconoce su nihilismo. ¿No será acaso el nihilismo un camino para este juego experimental? Dice Nietzsche: "[...] von Grund aus bisher Nihilist gewesen bin" (Nietzsche, 2016, p. 273 [eKGWB/NF-1887, 9(123)]). En su raíz misma ha sido nihilista, es la afirmación del filósofo.

La filosofia experimental evoca un sentido prometedor en la medida en que deja de lado la forma tradicional, al menos en habla hispana, de acercarse a Nietzsche y, por otro lado, intenta plantear un novedoso camino. El presente trabajo ciertamente es un ejercicio en sí mismo experimental en cuanto no lleva al lector, o así lo espera el autor de este texto, a conclusiones definitivas y con ello no terminamos con un cierre final. La filosofía experimental a fin de cuentas expresa un modo de pensamiento que en su propio carácter es azaroso y vacila constantemente. El devenir y la filosofia experimental ¿no será que comparten un mismo destino?

\section{Referencias bibliográficas}

Choque, O. (2018a). El filósofo y su filosofía. La 'filosofía experimental' de Nietzsche. Fragmentos de filosofia, 16, 1-21.

Choque, O. (2018b). Ciencia y creatividad en Friedrich Nietzsche. Con-Sciencias sociales, 19, 20-31.

Choque, O. (2019a). "Dios ha muerto" y la cuestión de la ciencia en Nietzsche. Estudios de Filosofia, 59, 139-166. https://doi.org/10.17533/udea. ef.n59a07

Choque, O. (2019b). Foucault: biopolítica y discontinuidad. Praxis Filosófica, (49), 191-218. https://doi.org/10.25100/pfilosofica.v0i49.8030

Choque, O. (2020a). El pensador bajo la máscara. Aporías a la filosofía experimental. Revista Filosofia UIS, 19 (2), 21-34. https://doi.org/10.18273/ revfil.v19n2-2020002

Choque, O. (2020b). Viscarra, Nietzsche: Las virtudes del genio y la comunicación de la "cultura superior". Revista Journal de Comunicación Social, 10 (10), 147165. https://doi.org/10.35319/jcomsoc.2020101225

Colli, G. (1983). Introducción a Nietzsche. (R. Medina, Trad.). Folios.

D’Iorio, P. (2010). La edición crítica digital de las obras y la correspondencia de Nietzsche. Estudios Nietzsche, 187-196. Recuperado de: https://www.uma.es/ nietzsche-seden/obra/eKGWB.pdf. Acceso el 27 de abril de 2018.

Figal, G. (2004). Nietzsche. Eine philosophische Einführung. Reclam.

Fink, E. (2017). La filosofia de Nietzsche. Alianza. 
Gerhardt, V. (1986). „Experimental-Philosophie“. Versuch einer Rekonstruktion. En M. Djuric \& J. Simon (Eds.), Kunst und Wissenschaft bei Nietzsche (pp. 45-61). Würzburg.

Heidegger, M. (2013). Nietzsche. Ariel.

Heit, H. (2012). Filosofía experimental. En C. Niemeyer (Ed.), Diccionario Nietzsche. Conceptos, obras, influencias y lugares (pp. 205-206). Biblioteca Nueva.

Heit, H. (2014). Ende der Säkularisierung? Nietzsche und die große Erzählung vom Tod Gottes. En C. Terne \& S. Dietzsche (Eds.), Nietzsches Perspektiven. Über Dichten und Denken in der Moderne (pp. 68-84). De Gruyter.

Hollingdale, R. J. (2016). Nietzsche. El hombre y su filosofia. Tecnos.

Kaulbach, F. (1980). Nietzsches Idee einer Experimentalphilosophie. Viena.

Müller, E. (2020). Nietzsche-Lexikon. Wilhelm Fink.

Niemeyer, C. (2012). Diccionario Nietzsche. Conceptos, obras, influencias y lugares (I. De los Ríos, S. Santana, J. L. Puertas, \& J. Planells, Trads.). Biblioteca Nueva. Nietzsche, F. (1973). El crepúsculo de los ídolos. Alianza

Nietzsche, F. (1980a). La genealogía de la moral. (A. Sánchez Pascual, Trad.). Alianza.

Nietzsche, F. (1980b). Sämtliche Werke. Studienausgabe in 15 Bänden. Herausgegeben von Giorgio Colli und Mazzino Montinari. Dtv-AusgabeMünchen.

Nietzsche, F. (1996a). Humano demasiado humano. (A. Brotons Muñoz, Trad.). Akal.

Nietzsche, F. (1996b). Ecce homo. (A. Sánchez Pascual, Trad.). Alianza.

Nietzsche, F. (1999). El caminante y su sombra (L. Díaz, Trad.). Edimat.

Nietzsche, F. (2007). La Gaya Ciencia. (A. Mardomingo, Trad.). Edaf.

Nietzsche, F. (2008). Fragmentos Póstumos. (1875-1882) Volumen II (M. Barrios $\&$ J. Aspiunza, Trads.). Tecnos.

Nietzsche, F. (2010). Fragmentos Póstumos. (1882-1885) Volumen III (D. Sánchez M. \& J. Conill, Trads.). Tecnos.

Nietzsche, F. (2012). El nacimiento de la tragedia (A. Sánchez Pascual, Trad.). Alianza.

Nietzsche, F. (2016). Fragmentos Póstumos. (1885-1889) Volumen IV (J. Vermal $\&$ J. Bautista, Trads.). Tecnos.

Nietzsche, F. (2017). Aurora (J. Aspiunza, Trad.). Tecnos.

Schwab, P. (2011a). Die tragische Überwindung des Nihilismus. Nietzsches 'Philosophie des Tragischen' von der Geburt der Tragödie bis zum Spätwerk. En L. Hühn \& P. Schwab (Eds), Die Philosophie des Tragischen (pp. 575-621). Philosophy of the Tragic. Schopenhauer - Schelling - Nietzsche. De Gruyter. https://doi.org/10.1515/9783110216639

Schwab, P. (2011b). Einleitung. En L. Hühn \& P. Schwab (Eds), Die Philosophie des Tragischen (pp. 1-16). Die Philosophie des Tragischen. SchopenhauerSchelling - Nietzsche. De Gruyter. https://doi.org/10.1515/9783110216639 
Schwab, P. (2014). Ethik und Ethikkritik. Philosophie von Existenz und bei Kierkegaard Nietzsche. En H. Feger \& M. Hackel (Eds.), Existenzphilosophie und Ethik (pp. 89-111). De Gruyter. https://doi.org/10.1515/9783110331103

Schwab, P. (2015). Critique of 'the System' and Experimental Philosophy Nietzsche and Kierkegaard". En K. Hay \& L. R. dos Santos (Eds.), Nietzsche, German Idealism and Its Critics (pp. 223-245). De Gruyter. https://doi. org/10.1515/9783110308181

Schwab, P. (2016). Interprétation et différence. Derrida lecteur de Nietzsche et de Heidegger. Les Cahiers philosophiques de Strasbourg, (39), 143-163. https:// doi.org/10.4000/cps. 326

Sommer, A. U. (2006). «Dios ha muerto» y «¿Dionisio contra el crucificado?» Sobre la crítica de Nietzsche a la religión y al cristianismo. Estudios Nietzsche, (6), 47-64. https://doi.org/10.24310/EstudiosNIETen.vi6.8708

Sommer, A. U. (2019). Nietzsche und die Folgen. J. B. Metzler.

Tría, E. (1987). El 'experimentum crucis' de la filosofía de Nietzsche. En Vermal, J. (Autor). La crítica de la metafisica en Nietzche (pp. 7-13). Anthropos. Tongeren, P. V. (1999). Reinterpreting Modern Culture: An introduction to Nietzsche's philosophy. West Lafayette.

Vattimo, G. (2001). Introducción a Nietzsche. Península. 